Review

\title{
Prevalence and Impact of Atrial Fibrillation in Hospitalized Patients with COVID-19: A Systematic Review and Meta-Analysis
}

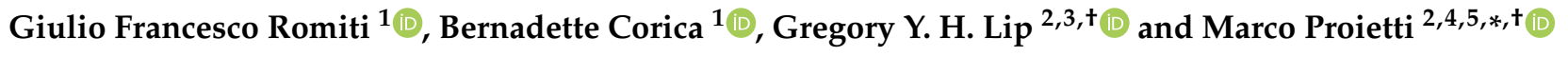 \\ 1 Department of Translational and Precision Medicine, Sapienza-University of Rome, 00161 Rome, Italy; \\ giuliofrancesco.romiti@uniroma1.it (G.F.R.); bernadette.corica@uniroma1.it (B.C.) \\ 2 Liverpool Centre for Cardiovascular Science, University of Liverpool and Liverpool Heart \& Chest Hospital, \\ Liverpool 14 3PE, UK; gregory.lip@liverpool.ac.uk \\ 3 Department of Clinical Medicine, Aalborg University, DK-9100 Aalborg, Denmark \\ 4 Geriatric Unit, IRCCS Istituti Clinici Scientifici Maugeri, 20138 Milan, Italy \\ 5 Department of Clinical Sciences and Community Health, University of Milan, 20122 Milan, Italy \\ * Correspondence: marco.proietti@unimi.it; Tel.: +39-02-5072-5150 \\ + Joint senior authors.
}

Citation: Romiti, G.F.; Corica, B.; Lip, G.Y.H.; Proietti, M. Prevalence and Impact of Atrial Fibrillation in Hospitalized Patients with COVID-19: A Systematic Review and Meta-Analysis. J. Clin. Med. 2021, 10, 2490. https://doi.org/10.3390/ jcm10112490

Academic Editor: Nandu Goswami

Received: 26 May 2021

Accepted: 2 June 2021

Published: 4 June 2021

Publisher's Note: MDPI stays neutral with regard to jurisdictional claims in published maps and institutional affiliations.

Copyright: (c) 2021 by the authors. Licensee MDPI, Basel, Switzerland. This article is an open access article distributed under the terms and conditions of the Creative Commons Attribution (CC BY) license (https:// creativecommons.org/licenses/by/ $4.0 /)$.

\begin{abstract}
Background: In patients with COVID-19, cardiovascular complications are common and associated with poor prognosis. Among these, an association between atrial fibrillation (AF) and COVID-19 has been described; however, the extent of this relationship is unclear. The aim of this study is to investigate the epidemiology of AF in COVID-19 patients and its impact on all-cause mortality. Methods: A systematic review and meta-analysis were performed and reported according to PRISMA guidelines, and a protocol for this study was registered on PROSPERO (CRD42021227950). PubMed and EMBASE were systematically searched for relevant studies. A random-effects model was used to estimate pooled odds ratios (OR) and 95\% confidence intervals (CI). Results: Overall, 31 studies were included in the analysis, with a total number of 187,716 COVID-19 patients. The prevalence of AF was found to be as high as 8\% of patients with COVID-19 (95\% CI: 6.3-10.2\%, 95\% prediction intervals (PI): 2.0-27.1\%), with a high degree of heterogeneity between studies; a multiple meta-regression model including geographical location, age, hypertension, and diabetes showed that these factors accounted for more than a third of the heterogeneity. AF COVID-19 patients were less likely to be female but more likely older, hypertensive, and with a critical status than those without AF. Patients with AF showed a significant increase in the risk of all-cause mortality (OR: 3.97, 95\% CI: 2.76-5.71), with a high degree of heterogeneity. A sensitivity analysis focusing on new-onset AF showed the consistency of these results. Conclusions: Among COVID-19 patients, AF is found in 8\% of patients. AF COVID-19 patients are older, more hypertensive, and more likely to have a critical status. In COVID-19 patients, AF is associated with a 4-fold higher risk of death. Further studies are needed to define the best treatment strategies to improve the prognosis of AF COVID-19 patients.
\end{abstract}

Keywords: atrial fibrillation; COVID-19; prognosis; outcomes

\section{Introduction}

From early 2020, COVID-19 has caused a high burden of morbidity and mortality worldwide [1]. Cardiovascular diseases were indicated among the leading causes of clinical deterioration and adverse outcomes in these patients [2], and the association between COVID-19 and cardiac arrhythmia has been described [3].

Atrial fibrillation (AF) is among the most common cardiac arrhythmias, and its association between infectious diseases and critical illness has already been reported [4,5], with a significant burden on management and prognosis [6,7]. Several hypotheses have been proposed to explain the relationship between AF and infection, including cytokine storm, 
inflammation, and oxidative stress $[5,8]$. All these phenomena are also commonly reported in COVID-19 patients [9].

Notwithstanding this, only few studies have reported about the onset of AF during COVID-19 [3,10], and the actual prevalence and the impact of AF on the prognosis of these patients are still unclear. On the other hand, AF is already recognized as the most common arrhythmia occurring during COVID-19 [3,11,12]. This emphasizes the potential for a tight relationship between these two diseases, as well as the clinical relevance of this association. Although previous systematic reviews and meta-analyses have investigated the relationship between AF and COVID-19, these were based on a limited number of patients, were not focused on the AF episodes occurring during COVID-19, or did not provide an extensive study of heterogeneity between studies [13-15]. A more comprehensive evaluation of the relationship between AF and COVID-19, also taking into account those factors that may influence the prevalence of AF and its related outcomes, is highly warranted to inform physicians involved in the frontline of this pandemic [16].

We aimed to perform a systematic review and meta-analysis of the prevalence of $\mathrm{AF}$, factors associated with its onset, and the impact on all-cause mortality in patients with COVID-19.

\section{Methods}

This systematic review was performed according to the Meta-analysis Of Observational Studies in Epidemiology (MOOSE) guidelines and reported according to the Preferred Reporting Items for Systematic Reviews and Meta-Analyses (PRISMA) guidelines. A protocol for this study was registered into the international prospective register of systematic reviews (PROSPERO), N. CRD42021227950.

\subsection{Search Strategy}

A systematic literature search was performed on PubMed and EMBASE databases, from inception to 10 March 2021. Relevant key terms were combined in the search strategy, including 'Sars-CoV-2', 'COVID-19', and 'atrial fibrillation'. The full search strategy is reported in Supplementary Materials (Supplementary Table S1).

\subsection{Studies Selection}

All articles retrieved from the literature search were systematically screened independently by two investigators (G.F.R. and B.C.) according to titles and abstracts. Each article included after the first screening phase was then evaluated independently by two investigators (G.F.R. and B.C.) according to full-text eligibility. Disagreements were resolved by collegial discussion with a third author (M.P.).

\subsection{Inclusion and Exclusion Criteria}

The main inclusion criteria were: (i) all studies reporting the prevalence of AF in hospitalized patients with COVID-19; (ii) all studies reporting outcomes (i.e., mortality) according to AF status in patients with COVID-19. For the purpose of this study, AF was defined as the occurrence of AF during COVID-19, as defined in the original studies, and irrespective of the previous history of AF. When a study reported on AF and atrial flutter together, we included all patients under the AF definition, unless a clear distinction was possible based on published data. We excluded studies on highly selected cohorts (e.g., only deceased patients) of patients with COVID-19, conference abstracts, comments, editorials, case reports, systematic reviews, and meta-analyses. In the case of duplicated cohorts (i.e., two or more studies based on the same cohort of patients), we selected the study with (i) the highest number of patients included, (ii) the most complete set of information, or (iii) the most recently published one. 


\subsection{Data Extraction and Quality Assessment}

Data from the studies included were independently extracted by two investigators (G.F.R. and B.C.) with the use of a standardized electronic form. We extracted data on sample size, numbers of patients with $\mathrm{AF}$, proportion of females, and prevalence of several comorbidities (including hypertension, diabetes mellitus, coronary artery disease (CAD), chronic heart failure (CHF), and chronic kidney disease (CKD)). We also extracted data on the proportion of "critical" patients; since studies heterogeneously reported characteristics related to COVID-19 severity, we defined "critical" patients as follows: (i) patients were admitted to the ICU, (ii) patients underwent mechanical ventilation, or (iii) patients were defined as "critical" in the original studies. Additionally, we extracted data regarding outcomes (in-hospital death or 30-day mortality) according to the AF status, when available.

All studies included were independently evaluated by two investigators (G.F.R. and B.C.) to assess the risk of bias. According to the outcomes investigated, we evaluated the risk of bias separately for each outcome of the study: for the prevalence of $\mathrm{AF}$, we assessed the risk of bias using a customized version of the Newcastle-Ottawa scale (NOS) for crosssectional studies, composed of five items across three domains (selection, comparability, outcome), with a maximum of 5 points. Any study with a score $\leq 3$ was categorized as being at a high risk of bias. For studies exploring outcomes according to AF status, we assessed the risk of bias using a customized version of the NOS for cohort studies [17], composed of eight items across three domains (selection, comparability, outcome). Any study with a score $\leq 6$ was categorized as being at a high risk of bias.

\subsection{Outcomes Definition}

Prevalence of AF was defined as the proportion of patients that present AF at admission or during the clinical course of COVID-19, as defined in the original studies.

We also investigated the association of AF with several conditions or baseline characteristics of the COVID-19 patients, including age, female sex, history of hypertension, diabetes mellitus, coronary artery disease (CAD), and chronic heart failure (CHF), as well as the critical disease status as previously defined.

All-cause mortality was defined as the occurrence of in-hospital death or 30-days death in patients with COVID-19, according to AF status.

\subsection{Statistical Analysis}

The prevalence of AF reported in the original studies included were pooled with a random intercept logistic regression model [18], and reported as pooled prevalence, $95 \%$ confidence intervals (CI), and 95\% prediction intervals (PI). PI represents a predicted range of the true effect in a potential future study, and provides useful information on the variability of the effect in different clinical settings [19,20].

Dichotomous variables were pooled and compared using random-effects models, and reported as odds ratios (OR) mean difference and 95\% CI. For continuous variables, mean, $\mathrm{SD}$, and total number in each group were pooled and compared with the inverse variance method; mean difference and $95 \% \mathrm{CI}$ were reported accordingly.

The inconsistency index $\left(\mathrm{I}^{2}\right)$ was calculated to measure heterogeneity. According to pre-specified cut-offs, low heterogeneity was defined as an $\mathrm{I}^{2}$ of $<25 \%$, moderate heterogeneity when $\mathrm{I}^{2}$ fell between 25 and $75 \%$, and high heterogeneity when $\mathrm{I}^{2}$ was $>75 \%$.

For prevalence of AF and all-cause mortality, a sensitivity analysis was performed with a "leave-one-out" approach, in which all studies are removed iteratively one at a time to evaluate their influence on the pooled estimate and heterogeneity. As an additional sensitivity analysis, we also computed the prevalence of AF according to the inverse variance method, with two types of transformation of the proportions (logit transformation and Freeman-Tukey double arcsine transformation).

To investigate the potential sources of heterogeneity in the pooled prevalence of $\mathrm{AF}$, we performed several subgroup analyses, according to geographical location, study design (retrospective vs. observational), and risk of bias. Moreover, we also performed univariable 
and multivariable meta-regression, according to study-level relevant baseline characteristics, to identify potential study-level characteristics associated with the prevalence of AF, or the risk of all-cause mortality in patients with AF vs. those without AF.

A sensitivity analysis, including only patients with new onset AF (i.e., patients who presented with AF during COVID-19, with the exclusion of those with a previous history of AF) was also performed for both the prevalence of AF and all-cause mortality. For this analysis, we excluded from the calculation those patients with a known history of AF. Only those studies for which these data were available (or derivable from the main cohort), and clearly referred to new onset $\mathrm{AF}$, were included in this analysis.

Publication bias was assessed for studies reporting all-cause mortality according to AF status, with the use of funnel plots, which were visually inspected for asymmetricity. Egger's test was also performed. In case of detection of significant publication bias, we performed further analysis according to the trim-and-fill approach [21], in which additional studies which correct for the asymmetry in the funnel plot are imputed and combined with those included in the meta-analysis to analyze the actual effect of potential publication bias.

All the statistical analyses were performed using $\mathrm{R}$ version 4.0.3 ( $\mathrm{R}$ Core Team, $\mathrm{R}$ Foundation for Statistical Computing, Vienna, Austria, 2020), with the use of 'meta' [22], 'metafor' [23], and 'dmetar' [24] packages.

\section{Results}

Of the 783 studies identified from the literature search (216 on Pubmed and 567 on EMBASE), 31 studies were selected according to the inclusion and exclusion criteria and included in the analysis [3,10-12,25-51] (Figure S1 in Supplementary Materials), with a total of 187,716 COVID-19 patients. Baseline characteristics of the studies included are reported in Table 1.

Thirteen studies were held in Europe $[10,11,25,29,31,33,37,39,42-44,47,50]$, nine in North America [3,28,30,32,41,45,46,49,51], four in Asia [26,34,35,48], and five in other geographical locations, including one multinational study $[12,27,36,38,40]$. Twenty-five studies were observational retrospective $[3,10,12,26,28,30-32,34,35,37-51]$, four were based on prospective observational analysis of single center cohorts $[11,25,29,36]$, while two were observational prospective multicenter studies [27,33].

Of the studies, 14 were included in the analysis for all-cause mortality according to AF status (12 reported in-hospital death [3,10,12,25,29,30,37,40-43,45] and two described 30 -day mortality [32,50]). Nine studies included patients with new onset AF [10,29,36,37, $40-42,45,51]$. To improve the reliability of our estimates, after careful evaluation of the definitions of AF used and of the data reported, for two studies [37,51], we decided to compute only new onset $\mathrm{AF}$ in the main analysis about prevalence.

The evaluation of bias for the two outcomes investigated is reported in Supplementary Materials (Tables S2 and S3, respectively). Among studies reporting the prevalence of AF, 13 studies were categorized as being at high risk of bias [11,32-34,36,37,39,42,44,46-48,51]; incomplete reporting of baseline characteristics was the most common concern. Among the studies reporting all-cause mortality according to AF, two studies were at high risk of bias $[42,50]$.

\subsection{Prevalence of AF in Patients with COVID-19}

In the 31 studies included, $8.0 \%$ of patients with COVID-19 presented AF (95\% CI: 6.3-10.2\%, 95\% PI: 2.0-27.1\%), with high heterogeneity between studies (Figure 1). The leave-one-out sensitivity analysis showed consistent results (Supplementary Figure S2); similar estimates were also found in the sensitivity analysis according to the inversevariance method, using different methods for transformation of the proportions (Supplementary Table S4). 
Table 1. Main characteristics of the studies included in the systematic review.

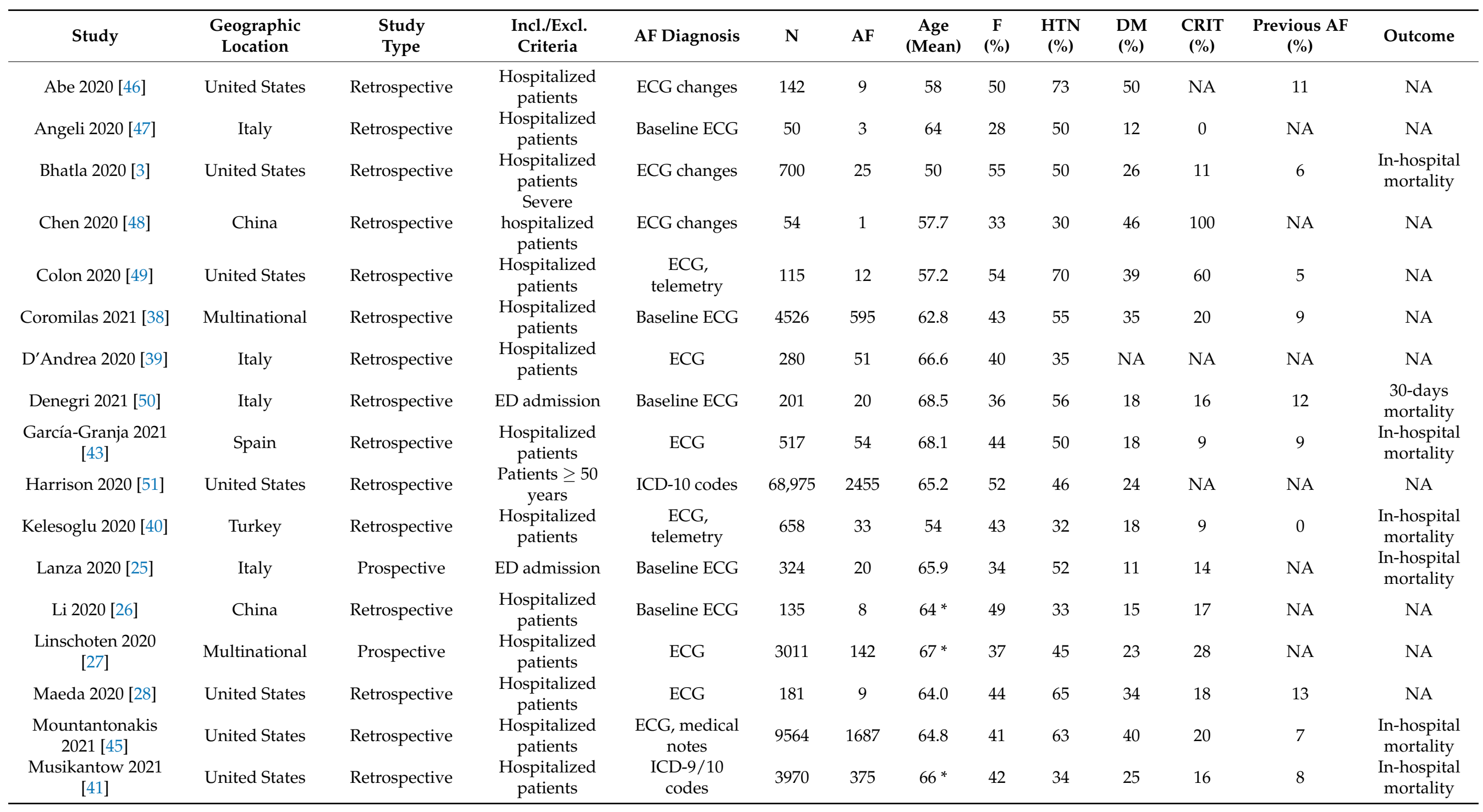


Table 1. Cont.

\begin{tabular}{|c|c|c|c|c|c|c|c|c|c|c|c|c|c|}
\hline Study & $\begin{array}{l}\text { Geographic } \\
\text { Location }\end{array}$ & $\begin{array}{l}\text { Study } \\
\text { Type }\end{array}$ & $\begin{array}{l}\text { Incl./Excl. } \\
\text { Criteria }\end{array}$ & AF Diagnosis & $\mathbf{N}$ & AF & $\begin{array}{c}\text { Age } \\
\text { (Mean) }\end{array}$ & $\begin{array}{c}F \\
(\%)\end{array}$ & $\begin{array}{c}\text { HTN } \\
(\%)\end{array}$ & $\begin{array}{l}\mathrm{DM} \\
(\%)\end{array}$ & $\begin{array}{l}\text { CRIT } \\
(\%)\end{array}$ & $\begin{array}{c}\text { Previous AF } \\
(\%)\end{array}$ & Outcome \\
\hline Pardo Sanz 2020 & Spain & Prospective & $\begin{array}{l}\text { Hospitalized } \\
\text { patients }\end{array}$ & $\begin{array}{l}\text { ECG, ECG } \\
\text { Holter }\end{array}$ & 160 & 12 & 65.7 & 40 & 47 & 16 & 4 & 19 & $\begin{array}{l}\text { In-hospital } \\
\text { mortality }\end{array}$ \\
\hline Peltzer 2020 [30] & United States & Retrospective & $\begin{array}{l}\text { Hospitalized } \\
\text { patients }\end{array}$ & $\begin{array}{c}\text { ECG, } \\
\text { telemetry }\end{array}$ & 1053 & 166 & 62.4 & 62 & 54 & 30 & 33 & 9 & $\begin{array}{c}\text { In-hospital } \\
\text { mortality }\end{array}$ \\
\hline Piroth 2020 [31] & France & Retrospective & $\begin{array}{l}\text { Hospitalized } \\
\text { patients }\end{array}$ & ICD-10 codes & 89,530 & 11,129 & 65 & 47 & 33 & 19 & 16 & NA & NA \\
\hline Poterucha 2020 [32] & United States & Retrospective & $\begin{array}{l}\text { Hospitalized } \\
\text { patients }\end{array}$ & Baseline ECG & 887 & 46 & 64.1 & 42 & 61 & 39 & NA & NA & $\begin{array}{l}\text { 30-days } \\
\text { mortality }\end{array}$ \\
\hline Rav-Acha 2020 [12] & Israel & Retrospective & $\begin{array}{l}\text { Hospitalized } \\
\text { patients }\end{array}$ & ECG changes & 390 & 20 & $57.5^{*}$ & 45 & 30 & 20 & 10 & 7 & $\begin{array}{c}\text { In-hospital } \\
\text { mortality }\end{array}$ \\
\hline Russo 2020 [10] & Italy & Retrospective & ED admission & Baseline ECG & 414 & 71 & 66 & 38 & 64 & 26 & NA & 17 & $\begin{array}{c}\text { In-hospital } \\
\text { mortality }\end{array}$ \\
\hline Sala 2020 [11] & Italy & Prospective & $\begin{array}{l}\text { Hospitalized } \\
\text { patients }\end{array}$ & Baseline ECG & 132 & 8 & 65 & 33 & 45 & 20 & 0 & 12 & NA \\
\hline Santoro 2020 [33] & Italy/Germany & Prospective & $\begin{array}{l}\text { Hospitalized } \\
\text { patients }\end{array}$ & Baseline ECG & 110 & 6 & 58 & 33 & 39 & 13 & 6 & NA & NA \\
\hline Spinoni 2021 [42] & Italy & Retrospective & $\begin{array}{l}\text { Hospitalized } \\
\text { patients }\end{array}$ & ECG & 637 & 134 & NA & NA & NA & NA & NA & NA & $\begin{array}{c}\text { In-hospital } \\
\text { mortality }\end{array}$ \\
\hline Wang 2020 [35] & China & Retrospective & $\begin{array}{l}\text { Hospitalized } \\
\text { patients }\end{array}$ & Baseline ECG & 319 & 20 & 65 & 52 & 44 & 23 & 30 & NA & NA \\
\hline Wetterslev 2021 [44] & Denmark & Retrospective & $\begin{array}{l}\text { Severe } \\
\text { hospitalized } \\
\text { patients }\end{array}$ & $\begin{array}{l}\text { ECG, medical } \\
\text { notes }\end{array}$ & 155 & 52 & $66^{*}$ & 27 & 44 & 21 & 100 & NA & NA \\
\hline Yenerçag 2020 [36] & Turkey & Prospective & $\begin{array}{l}\text { Hospitalized } \\
\text { patients w/out } \\
\text { AF, CKD, HF }\end{array}$ & ECG changes & 140 & 13 & 51.7 & 51 & 47 & 34 & NA & 0 & NA \\
\hline Zylla 2021 [37] & Germany & Retrospective & $\begin{array}{l}\text { Hospitalized } \\
\text { patients }\end{array}$ & ECG changes & 139 & 11 & 61.1 & 34 & 43 & 19 & 39 & 0 & $\begin{array}{c}\text { In-hospital } \\
\text { mortality }\end{array}$ \\
\hline
\end{tabular}

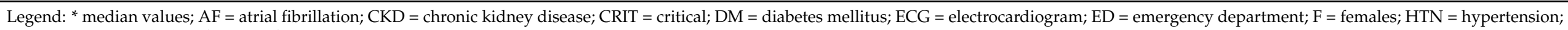
$\mathrm{ICD}=$ International Classification of Diseases; $\mathrm{NA}=$ not available. 


\begin{tabular}{|c|c|c|c|}
\hline Study & Events & Total & GLMM, Random, 95\% CI \\
\hline Vee 2020 [34] & 2 & 247 & $0.008(0.001 ; 0.029)$ \\
\hline Chen 2020 [48] & 1 & 54 & $0.019(0.000 ; 0.099)$ \\
\hline Harrison 2020 [51] & 2455 & 68975 & $0.036(0.034 ; 0.037)$ \\
\hline Bhatla 2020 [3] & 25 & 700 & $0.036(0.023 ; 0.052)$ \\
\hline Linschoten 2020 [27] & 142 & 3011 & $0.047(0.040 ; 0.055)$ \\
\hline Maeda 2020 [28] & 9 & 181 & $0.050(0.023 ; 0.092)$ \\
\hline Kelesoglu 2020 [40] & 33 & 658 & $0.050(0.035 ; 0.070)$ \\
\hline Rav-Acha 2020 [12] & 20 & 390 & $0.051(0.032 ; 0.078)$ \\
\hline Poterucha 2020 [32] & 46 & 887 & $0.052(0.038 ; 0.069)$ \\
\hline Santoro 2020 [33] & 6 & 110 & $0.055(0.020 ; 0.115)$ \\
\hline Li 2020 [26] & 8 & 135 & $0.059(0.026 ; 0.113)$ \\
\hline Angeli 2020 [47] & 3 & 50 & $0.060(0.013 ; 0.165)$ \\
\hline Sala 2020 [11] & 8 & 132 & $0.061(0.027 ; 0.116)$ \\
\hline Lanza 2020 [25] & 20 & 324 & $0.062(0.038 ; 0.094)$ \\
\hline Wang 2020 [35] & 20 & 319 & $0.063(0.039 ; 0.095)$ \\
\hline Abe $2020[46]$ & 10 & 142 & $0.070(0.034 ; 0.126)$ \\
\hline Pardo Sanz 2020 [29] & 12 & 160 & $0.075(0.039 ; 0.127)$ \\
\hline Zylla 2021 [37] & 11 & 139 & $0.079(0.040 ; 0.137)$ \\
\hline Yenerçag 2020 [36] & 13 & 140 & $0.093(0.050 ; 0.154)$ \\
\hline Musikantow 2021 [41] & 375 & 3970 & $0.094(0.086 ; 0.104)$ \\
\hline Denegri 2021 [50] & 20 & 201 & $0.100(0.062 ; 0.149)$ \\
\hline Colon 2020 [49] & 12 & 115 & $0.104(0.055 ; 0.175)$ \\
\hline García-Granja 2021 [43] & 54 & 517 & $0.104(0.079 ; 0.134)$ \\
\hline Piroth 2020 [31] & 11129 & 89530 & $0.124(0.122 ; 0.126)$ \\
\hline Coromilas 2021 [38] & 595 & 4526 & $0.131(0.122 ; 0.142)$ \\
\hline Peltzer 2020 [30] & 166 & 1053 & $0.158(0.136 ; 0.181)$ \\
\hline Russo 2020 [10] & 71 & 414 & $0.171(0.136 ; 0.211)$ \\
\hline Mountantonakis 2021 [45] & 1687 & 9564 & $0.176(0.169 ; 0.184)$ \\
\hline D'Andrea 2020 [39] & 51 & 280 & $0.182(0.139 ; 0.232)$ \\
\hline Spinoni 2021 [42] & 134 & 637 & $0.210(0.179 ; 0.244)$ \\
\hline Wetterslev 2021 [44] & 52 & 155 & $0.335(0.262 ; 0.416)$ \\
\hline Total (95\% CI) & \multirow{2}{*}{\multicolumn{2}{|c|}{187716}} & $0.080(0.063 ; 0.102)$ \\
\hline Prediction interval & \multirow{2}{*}{\multicolumn{3}{|c|}{$=4512.37, \mathrm{df}$}} \\
\hline Heterogeneity: $\mathrm{Tau}^{2}=0.487$ & & & \\
\hline
\end{tabular}

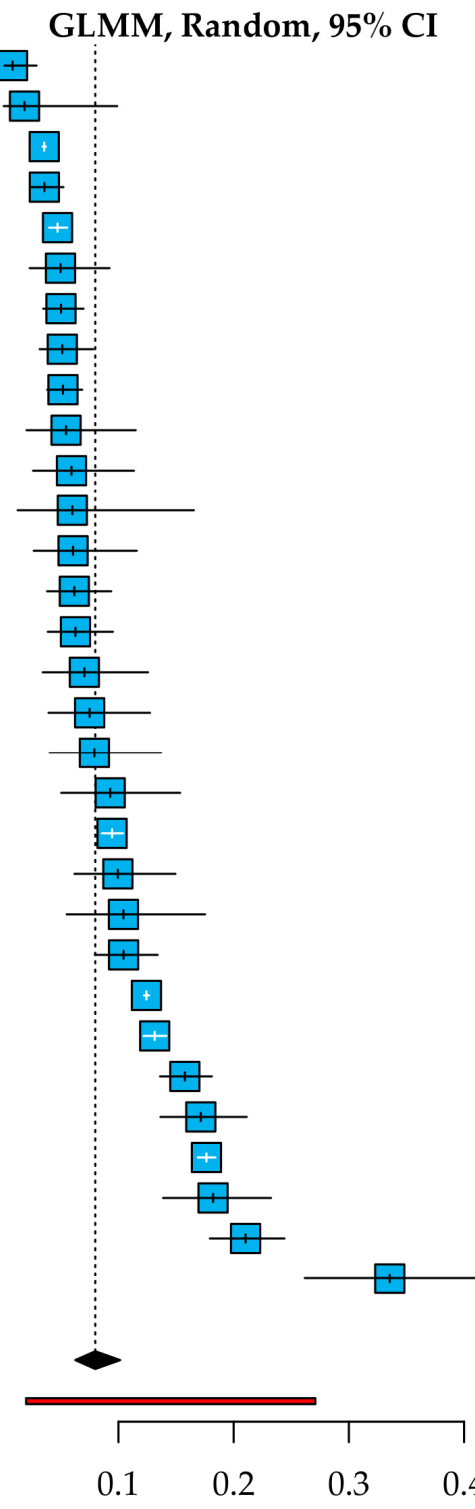

Figure 1. Pooled prevalence of AF in COVID-19 patients. Legend: CI = confidence interval; GLMM = general linear mixed model.

Pre-specified subgroup analyses are reported in Supplementary Table S5. Significant differences were observed according to the geographical location of the included studies, with the European-based cohorts showing a higher prevalence of $\mathrm{AF}(11.3 \%)$ compared to other studies performed in North America or Asia/other geographical locations (7.5\% and $5.3 \%$, respectively). No significant differences were observed according to the study design or the risk of bias.

The results of the meta-regressions are reported in Table 2. At univariable analysis, only age and hypertension resulted significantly and directly associated to the prevalence of AF; a similar, non-significant trend was also observed for geographical location and diabetes (Table 2). A multivariable meta-regression model comprising geographical location, mean age, history of hypertension, and history of diabetes was able to explain part of the heterogeneity observed $\left(R^{2}=46.0 \%, p=0.019\right)$. A graphical representation of the relationship between the mean age of studies included and the prevalence of AF is reported in Figure 2. 
Table 2. Univariable and multiple meta-regression * analysis for AF prevalence.

\begin{tabular}{|c|c|c|c|c|c|c|}
\hline Variable & Coefficient & Standard Error & Lower $95 \%$ CI & Upper $95 \%$ CI & $p$ & $\mathbf{R}^{2}$ \\
\hline \multicolumn{7}{|l|}{ Univariable Analysis } \\
\hline Age & 0.054 & 0.016 & 0.021 & 0.087 & 0.003 & 0.289 \\
\hline Female sex & 0.101 & 1.854 & -3.710 & 3.911 & 0.957 & 0.000 \\
\hline Hypertension & 2.058 & 0.881 & 0.247 & 3.869 & 0.028 & 0.143 \\
\hline Diabetes & 1.826 & 1.130 & -0.501 & 4.153 & 0.119 & 0.117 \\
\hline $\begin{array}{c}\text { Geographical location } \\
\text { Europe (ref.) }\end{array}$ & & & & & 0.067 & 0.191 \\
\hline North America & -0.331 & 0.277 & -0.900 & 0.238 & 0.242 & \\
\hline Asia/other & -0.702 & 0.287 & -1.291 & -0.113 & 0.021 & \\
\hline Multiple Analysis & & & & & 0.019 & \\
\hline Age & 0.041 & 0.018 & 0.002 & 0.079 & 0.038 & \\
\hline Hypertension & 0.115 & 1.357 & -2.692 & 2.922 & 0.933 & \\
\hline Diabetes & 3.081 & 1.855 & -0.756 & 6.917 & 0.110 & 0460 \\
\hline $\begin{array}{c}\text { Geographical location } \\
\text { Europe (ref.) }\end{array}$ & & & & & & 0.460 \\
\hline North America & -0.676 & 0.344 & -1.387 & 0.036 & 0.062 & \\
\hline Asia/other & -0.589 & 0.348 & -1.308 & 0.131 & 0.104 & \\
\hline
\end{tabular}

Legend: * Maximum likelihood; for other acronyms, please see previous tables legends.

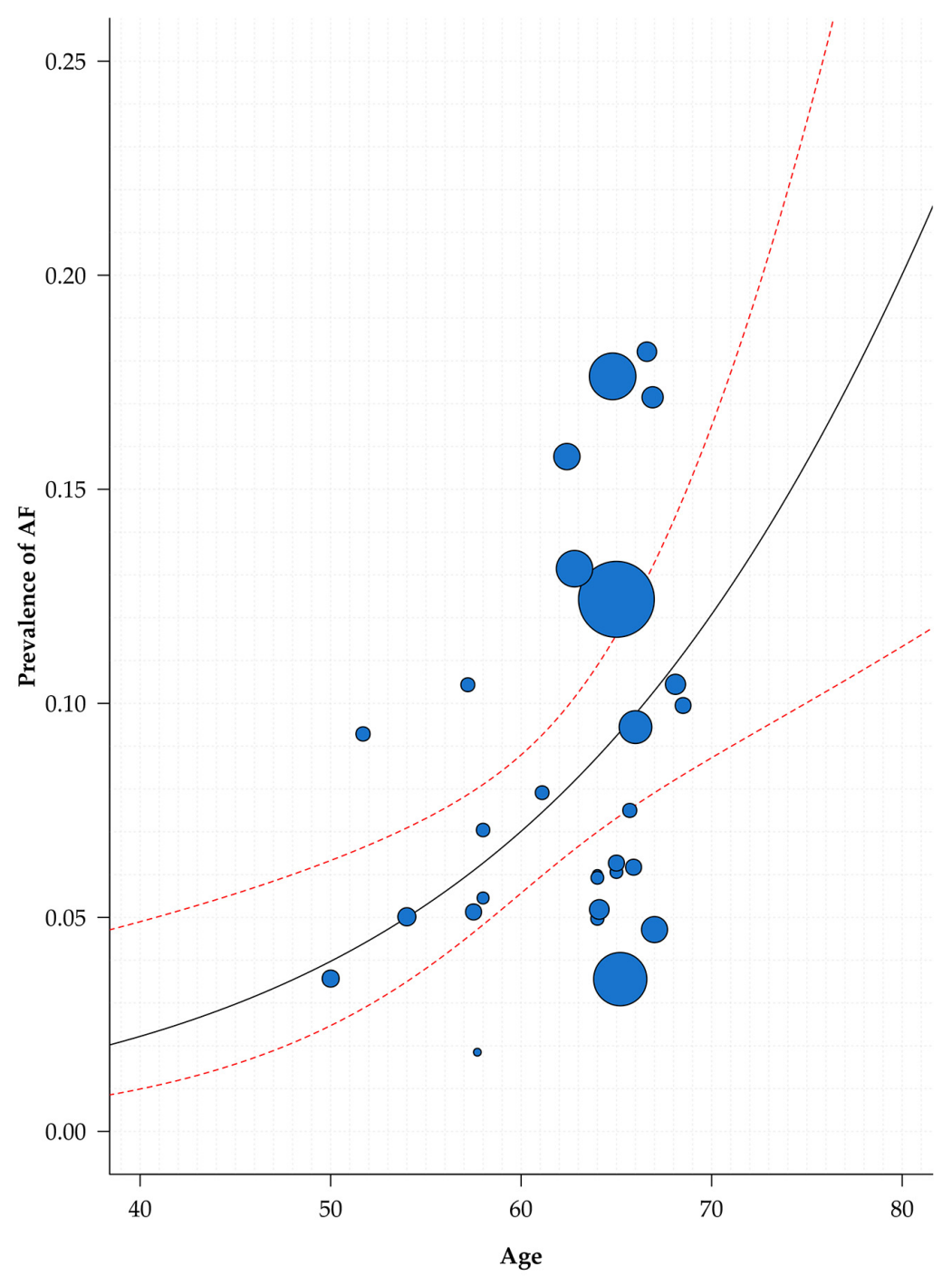

Figure 2. Relationship between age and $\mathrm{AF}$ prevalence in COVID-19 patients. Legend: $\mathrm{AF}=$ atrial fibrillation . 


\subsection{Clinical Characteristics of AF Patients with COVID-19}

We compared several baseline characteristics and conditions between patients presenting with and without AF. Eight studies reported data disaggregated by AF diagnosis on proportion of female sex, hypertension, and diabetes [10,29,30,37,40,41,43,45]; seven reported about mean age $[10,29,30,37,40,43,45]$ and CHF [10,29,30,40,41,43,45], while six reported on CAD [10,29,30,41,43,45]; finally, 12 reported on proportion of critical patients $[3,26,29,30,35,37,40,41,45,48,49]$ (specifically, six according to ICU admission $[3,26,29,30,43,49]$, two according to "critically ill" definition [35,48], one according to ICU/intermediate care unit admission [37], and two according to patients receiving mechanical ventilation [41,45]).

Results for this analysis are reported in Table 3. AF was associated with older age (mean difference: 13.2 years, 95\% CI 10.5-15.9) and a 17\% lower likelihood of being female. AF patients were more likely affected by hypertension, diabetes mellitus, CAD, or CHF; finally, they had a 3.6-fold higher chance of having a critical COVID-19 clinical course. Low to moderate heterogeneity was found for all analyses, except for mean age, which showed high heterogeneity $\left(\mathrm{I}^{2}=86 \%\right)$.

Table 3. Association of clinical characteristics with AF.

\begin{tabular}{|c|c|c|c|c|}
\hline Variable & $\mathbf{N}^{\circ}$ Studies & MD & $95 \% \mathrm{CI}$ & $I^{2}$ \\
\hline \multicolumn{5}{|c|}{ Continuous Variables } \\
\hline Age & 7 & 13.2 & $10.5-15.9$ & $86 \%$ \\
\hline Variable & $\mathbf{N}^{\circ}$ Studies & OR & $95 \%$ CI & $\mathrm{I}^{2}$ \\
\hline \multicolumn{5}{|c|}{ Categorical Variables } \\
\hline Female sex & 8 & 0.83 & $0.76-0.90$ & $7 \%$ \\
\hline Hypertension & 8 & 2.49 & $2.25-2.75$ & $0 \%$ \\
\hline Diabetes & 8 & 1.38 & $1.24-1.54$ & $0 \%$ \\
\hline CHF & 7 & 4.45 & $3.21-6.18$ & $58 \%$ \\
\hline CAD & 6 & 2.57 & $2.05-3.21$ & $58 \%$ \\
\hline Critical status & 12 & 3.62 & $2.39-5.48$ & $69 \%$ \\
\hline
\end{tabular}

Legend: $\mathrm{AF}=$ atrial fibrillation; $\mathrm{CAD}=$ coronary artery disease; $\mathrm{CHF}=$ congestive heart failure; $\mathrm{CI}=$ confidence interval; $\mathrm{MD}=$ mean difference; $\mathrm{OR}=$ odds ratio.

\subsection{All-Cause Mortality according to AF Status}

In the 14 studies reporting on all-cause mortality among COVID-19 patients and according to AF status, patients with AF showed a 4-fold higher risk of death compared to patients without AF (OR: 3.97, 95\%CI: 2.76-5.71, Figure 3), with high heterogeneity found between studies $\left(\mathrm{I}^{2}=78 \%\right)$. The leave-one-out analysis showed little to no effect of single studies on the results (Figure S3).

\begin{tabular}{|c|c|c|c|c|c|c|}
\hline & & AF & & No AF & & Odds Ratio \\
\hline Study & Events & Total & Events & Total & Weight & MH, Random, $95 \%$ CI \\
\hline Russo 2020 [10] & 21 & 71 & 86 & 343 & $8.5 \%$ & $1.26(0.71 ; 2.21)$ \\
\hline Mountantonakis 2021 [45] & 672 & 1238 & 460 & 1238 & $10.5 \%$ & $2.01(1.71 ; 2.36)$ \\
\hline Musikantow 2021 [41] & 171 & 375 & 933 & 3595 & $10.3 \%$ & $2.39(1.93 ; 2.97)$ \\
\hline Spinoni 2021 [42] & 59 & 134 & 111 & 503 & $9.5 \%$ & $2.78(1.86 ; 4.15)$ \\
\hline Kelesoglu 2020 [40] & 2 & 33 & 12 & 625 & $3.7 \%$ & $3.30(0.71 ; 15.37)$ \\
\hline García-Granja 2021 [43] & 27 & 54 & 103 & 463 & $8.4 \%$ & $3.50(1.96 ; 6.22)$ \\
\hline Peltzer 2020 [30] & 65 & 166 & 119 & 887 & $9.7 \%$ & $4.15(2.88 ; 5.99)$ \\
\hline Zylla 2021 [37] & 4 & 11 & 14 & 128 & $4.3 \%$ & $4.65(1.21 ; 17.91)$ \\
\hline Poterucha 2020 [32] & 27 & 46 & 181 & 841 & $8.2 \%$ & $5.18(2.82 ; 9.53)$ \\
\hline Rav-Acha 2020 [12] & 6 & 20 & 23 & 370 & $5.7 \%$ & $6.47(2.27 ; 18.39)$ \\
\hline Bhatla 2020 [3] & 6 & 25 & 24 & 675 & $5.9 \%$ & $8.57(3.14 ; 23.38)$ \\
\hline Pardo Sanz 2020 [29] & 4 & 12 & 7 & 148 & $4.1 \%$ & $10.07(2.43 ; 41.67)$ \\
\hline Lanza 2020 [25] & 7 & 20 & 13 & 304 & $5.5 \%$ & $12.05(4.12 ; 35.27)$ \\
\hline Denegri 2021 [50] & 14 & 20 & 28 & 181 & $5.7 \%$ & $12.75(4.52 ; 35.99)$ \\
\hline Total $(95 \% \mathrm{CI})$ & & 2225 & & 10301 & $100.0 \%$ & $3.97(2.76 ; 5.71)$ \\
\hline
\end{tabular}

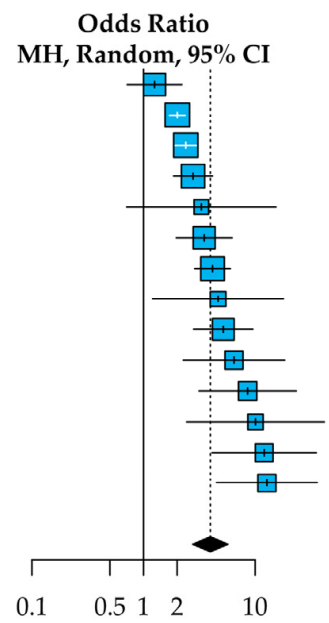

Figure 3. Risk of all-cause mortality in AF vs. non-AF patients. Legend: $\mathrm{AF}=$ atrial fibrillation; $\mathrm{CI}=$ confidence interval; MH = Mantel-Haenszel. 
Subgroup analyses according to the outcome definition are reported in Figure S4. Twelve studies reported in-hospital death $[3,10,12,25,29,30,37,40-43,45]$ and two reported 30 -days mortality $[32,50]$. Patients with AF showed both higher risk of in-hospital mortality (OR 3.52, 95\% CI 2.44-5.10) and 30-days mortality (OR 7.34, 95\% CI: 3.11-17.34), with no statistically significant difference between subgroups ( $p=0.12$; Figure S4).

Finally, we performed univariable and multivariable meta-regression analyses for allcause mortality. None of the predictors examined were found to be significantly associated with risk of all-cause death (Table S6).

Significant publication bias was found across the 13 studies included in the analysis (Egger's test $p=0.002$, Figure S5). Visual inspection of the funnel plot revealed a void in the lower-left part of the diagram. The correction of the asymmetry of the funnel plot according to the trim-and-fill approach did not affect the significance of the results, despite lowering the pooled estimate (OR: $2.49,95 \%$ CI: 1.58-3.92), suggesting that publication bias is unlikely to contribute to the overall significance of our results.

\subsection{Sensitivity Analysis about New-Onset AF}

In this pre-specified sensitivity analysis about COVID-19 patients with a new-onset AF (thus with the exclusion of those with a diagnosis of AF before occurrence of COVID-19), nine studies were included for the prevalence of $\operatorname{AF}[10,29,36,37,40,41,45,51]$ and five for all-cause mortality according to the AF status [10,37,40,42,45]. The prevalence of new-onset AF was found as high as 7.4\% (95\% CI: 5.3-10.2\%, Figure S6 Panel A in Supplementary Materials), with a high grade of heterogeneity found between studies. New-onset AF was also associated with a significant 2.4-fold higher risk of all-cause mortality compared to patients with no AF (Figure S6, Panel B), with a low degree of heterogeneity found between studies.

\section{Discussion}

In this systematic review and meta-analysis of 187,716 adults, $\mathrm{AF}$ was found in $8 \%$ of COVID-19 patients; high heterogeneity was found between studies, and the $95 \%$ PI indicated that actual prevalence of AF maybe up to 27\%. AF COVID-19 patients were more likely to be older, hypertensive, diabetic, with concomitant $\mathrm{CAD}$ and $\mathrm{CHF}$, and in a critical clinical status. Third, the presence of AF in COVID-19 patients was associated with a 4-fold higher risk of death. Overall, there was consistency in all the sensitivity analyses performed, even if confined to patients with new-onset AF.

Previous meta-analyses tried to investigate the relationship between AF and COVID19. However, these were based on significantly fewer studies and patients, and provided no information on the potential reasons of the heterogeneity found $[13,15]$; similarly, another systematic review that focused on outcomes [14] was not specifically designed to assess the prognostic role of AF developing during COVID-19, since it also included those studies that reported outcomes according to a pre-existing history of AF.

Compared to these previous reports, our study has several strengths. First, we provided a comprehensive and updated search and included more studies and a higher number of patients, encompassing both the epidemiology of AF and the related risk of death in patients with COVID-19; second, we focused only on those AF episodes that developed during COVID-19, so that the relationship observed may be more clinically relevant compared to that between history of AF and COVID-19; third, we calculated and reported $95 \%$ PI for our estimates of AF prevalence, providing information on the variability of the prevalence in different clinical settings [19,20]; finally, we performed an extensive assessment of the heterogeneity observed between studies, identifying potential moderators of the association between COVID-19 and AF.

Our findings make it possible to postulate on the pathophysiological mechanisms underlying the association between AF and COVID-19. The relationship between infections, inflammation, and the onset of $\mathrm{AF}$ is well known, although not completely explained [5]. Cytokine storm, oxidative stress, and atrial remodeling are among the putative phenomena 
that may trigger the onset of $\mathrm{AF}$, especially in patients with an individual predisposition [5]; moreover, inflammation has been linked to complex cellular changes in atrial myocardiocytes, which can ultimately contribute to the development of an arrhythmogenic milieu [52]. COVID-19 has been described from inception as an inflammatory disease [53], and targeting the dysregulated immune response was postulated as a promising therapeutic approach [54-58]. Indeed, the relationship between AF and COVID-19 may be-at least partially - explained by the increased burden of systemic inflammation. For example, higher levels of C-reactive protein and interleukin- 6 were observed in COVID-19 patients with AF, compared to patients without AF [37].

Inflammation may also trigger arrhythmias through determining a more severe clinical course of COVID-19. Inflammatory burden during COVID-19 was associated with greater disease severity [59] and increased risk of death [60]. On the other hand, the association between critically ill status and the onset of AF is well established, particularly during infections [7]; indeed, AF in our study was associated with a five-fold greater chance of having a critical clinical state.

Taken together, these findings may be interpreted as the results of a complex interplay between systemic inflammation, clinical status, and the onset of AF. Consistently, inflammation has been indicated as one key risk factor that may trigger AF onset during critical illness [61], and these multiple interacting mechanisms may also be involved in patients with COVID-19.

The prevalence of AF that we found is consistent with other studies focused on nonCOVID-19 pneumonia, which reported similar or slightly higher prevalence of AF [62,63]. Although a higher prevalence of AF may have been expected in COVID-19 patients, two remarks should be made. First, the mean age and the burden of comorbidities found in most studies were relatively low, compared to usual general population AF cohorts, thus indicating an overall low individual risk of AF. Second, significant heterogeneity was found between studies, with the $95 \%$ PI pointing towards a potentially higher prevalence of AF in further studies. Due to inconsistent reporting in the (early) original studies, only few factors were available for our meta-regression analysis, which showed that the combination of age, hypertension, diabetes mellitus, and geographical location may explain more than $40 \%$ of the heterogeneity observed. Even amongst the subset of studies investigating new-onset AF, the results indicate that the burden of risk factors may have a major role in the development of arrhythmia. While the strict relationship between increasing age and AF is largely known [64], as well as the association between older age and increased mortality during COVID-19 [65], our data help underline how older age may represent a "proxy" for clinical complexity, providing a substrate for developing conditions strongly connected with clinical complexity and multimorbidity, such as AF [66]. Consistently, a recent systematic review showed that increasing age, male sex, and cardiovascular comorbidities were strong risk factors for the onset of AF in ICU patients [61]; the association between these conditions, as well as multimorbidity, with disease severity and worse prognosis in patients with COVID-19 has also already been highlighted $[67,68]$. These findings suggest that AF may represent a "marker" of additional risk in COVID-19 patients. Indeed, patients with AF have a 4-fold increased risk of all-cause death.

The link between AF and mortality in COVID-19 patients could be explained by several mechanisms. Beyond the relationship with inflammation and multimorbidity, AF may directly worsen prognosis through hemodynamic instability, thromboembolism [69], and increased endothelial dysfunction [70]. Additionally, the results of the meta-regression analysis, which did not identify any moderators of the risk of mortality, strengthen the idea that AF may have a direct effect in increasing mortality in COVID-19 patients. This hypothesis is also supported by our sensitivity analysis on patients with new-onset AF, which showed a consistent 2.8-fold high risk of all-cause death, and by the disaggregated analysis of in-hospital mortality and 30-days mortality, which gave broadly comparable results. The phenotype of AF, including duration and recurrent episodes, may also impose different prognosis in COVID-19 patients; however, due to insufficient data reported in the original 
studies, we were unable to explore the contribution of specific AF characteristics on the risk of all-cause mortality in these patients. Moreover, uncertainties exist on the risk of AF recurrence in the long-term follow-up of patients with COVID-19. One large study found that over one third of patients with infection-related AF presented arrhythmia recurrence in the first year of follow-up [4], but whether this also applies to the COVID-19 scenario needs to be identified and confirmed, as well as the potential predictors of AF recurrence.

Finally, our results leave questions open on the appropriate management of patients who develop AF during COVID-19, particularly regarding thromboembolic risk and the implementation of antithrombotic treatment. The role of specific therapies, including immune modulators, antiarrhythmics, and antithrombotics on the prognosis of AF and COVID-19 patients is still far from being elucidated, and further studies are needed to understand whether specific strategies may have an influence on the outcome of these subjects. Although no definitive guidance exists on the management of new-onset AF occurring during infections, a recent large study found that these patients may experience a high thromboembolic risk [4], suggesting that they may need to be managed similarly to patients with non-infection related AF, also consistent with the pathophysiological hypotheses reported above. Moreover, the choice of antiarrhythmics for patients who develop AF during infections is still an open debate, although some potentially relevant prognostic differences were outlined recently [71,72]. Ultimately, the role of immunomodulating therapies in this clinical scenario is still unclear and needs further specific investigation [73]. From a broader perspective, as AF occurring during COVID-19 may indicate increased clinical complexity, these patients should be carefully evaluated for the presence of other clinical conditions. The use of an integrated approach which aims, among other things, at the optimal management of comorbidities, is currently endorsed by the recent European AF guidelines [64], and was found to be effective in improving prognosis [74]. It is plausible that a similar approach would also be beneficial in the clinical settings of patients who experience AF during COVID-19, although further studies are needed to define the prognosis and the optimal management of these subjects.

\section{Limitations}

Our study has several limitations. First, most studies were retrospective or not specifically designed to estimate the prevalence of AF or its effect on outcomes. However, this is a common limitation of many epidemiologic studies investigating the relationship between comorbidities and COVID-19; moreover, we provided 95\% PI values, which are useful to quantify the amount of uncertainty in our estimates, and performed metaregressions to investigate potential sources of heterogeneity. Second, the definition of "critical clinical disease" that we used may be prone to bias. However, the association between AF and critical status was strong, with moderate heterogeneity between studies. Third, a clear distinction between patients with new-onset AF and patients with both AF and previous history of arrhythmias was available only in a subset of studies. Nonetheless, the sensitivity analysis based on new-onset AF showed consistent results compared to the main analysis. Fourth, according to the data availability from the original studies, we were unable to assess the impact of other potentially relevant study-level characteristics (including other comorbidities and previous medical conditions, smoking habit, alcohol use, etc.) on the epidemiology of AF during COVID-19, as well as their impact on prognosis. Finally, we were unable to explore inflammatory burden differences between AF and nonAF patients, as well as the impact of different types and duration of AF episodes, or the contribution of a specific treatment, on the prognosis of COVID-19 patients, since most studies did not report laboratory parameters according to the AF status, information on AF phenotype, or data on the prognosis according to treatment received.

\section{Conclusions}

In this systematic review and meta-analysis, the prevalence of $\mathrm{AF}$ was $8 \%$ patients with COVID-19, and was associated with older age, male sex, hypertension, and critical 
status. Patients with AF showed a 4-fold higher risk of all-cause mortality compared to those without AF. Similar findings were observed in patients with new-onset AF. Our analysis underlines the detrimental role of AF in patients with COVID-19 and supports the need for the implementation of specific and tailored strategies for the prevention, diagnosis, and management of patients with COVID-19 and concurrent AF. Further studies are needed to define the optimal strategies for the follow-up of these patients, particularly regarding antithrombotic strategies.

Supplementary Materials: The following are available online at https:/ /www.mdpi.com/article/10 .3390/jcm10112490/s1: Table S1: Full Search Strategy, Table S2: Bias Assessment-NOS for prevalence of AF, Table S3: Bias Assessment-NOS for outcomes according to AF, Table S4: Sensitivity Analysis for the prevalence of AF according to different analysis methods, Table S5: Pre-specified subgroup analysis for AF prevalence, Table S6: Univariable and Multivariable Meta-Regression Analysis for All-Cause Mortality, Figure S1: PRISMA Flow-Chart of the Study, Figure S2: Leave one out analysis for prevalence of AF, Figure S3: Leave one out analysis for all-cause mortality according to AF, Figure S4: Subgroup analysis according to definition of all-cause mortality (In-hospital mortality vs. 30-days mortality), Figure S5: Publication Bias for all-cause mortality according to AF, Figure S6: Sensitivity analysis on New-Onset AF.

Author Contributions: G.F.R. and M.P. had full access to all of the data in the study and take responsibility for the integrity of the data and the accuracy of the data analysis, including and especially any adverse effects. G.F.R. and B.C. performed the search and the screening of the results; G.F.R. performed the analysis; G.F.R. and M.P. conceived the study, interpreted results, and drafted the manuscript; B.C. and G.Y.H.L. gave substantial intellectual contribution in reviewing the manuscript. All authors have read and agreed to the published version of the manuscript.

Funding: G.F.R. and B.C. were supported by grants (AR11916B84DD8DCE and AR120172B872270D) issued by Sapienza-University of Rome, Rome, Italy.

Conflicts of Interest: G.Y.H.L.: consultant for Bayer/Janssen, BMS/Pfizer, Medtronic, Boehringer Ingelheim, Novartis, Verseon, and Daiichi-Sankyo. Speaker for Bayer, BMS/Pfizer, Medtronic, Boehringer Ingelheim, and Daiichi-Sankyo. No fees were received personally. The other authors declare no significant conflict of interest.

\section{References}

1. Huang, C.; Wang, Y.; Li, X.; Ren, L.; Zhao, J.; Hu, Y.; Zhang, L.; Fan, G.; Xu, J.; Gu, X.; et al. Clinical Features of Patients Infected with 2019 Novel Coronavirus in Wuhan, China. Lancet 2020, 395, 497-506. [CrossRef]

2. Nishiga, M.; Wang, D.W.; Han, Y.; Lewis, D.B.; Wu, J.C. COVID-19 and Cardiovascular Disease: From Basic Mechanisms to Clinical Perspectives. Nat. Rev. Cardiol. 2020, 17, 543-558. [CrossRef]

3. Bhatla, A.; Mayer, M.M.; Adusumalli, S.; Hyman, M.C.; Oh, E.; Tierney, A.; Moss, J.; Chahal, A.A.; Anesi, G.; Denduluri, S.; et al. COVID-19 and Cardiac Arrhythmias. Heart Rhythm 2020, 17, 1439-1444. [CrossRef]

4. Gundlund, A.; Olesen, J.B.; Butt, J.H.; Christensen, M.A.; Gislason, G.H.; Torp-Pedersen, C.; Køber, L.; Kümler, T.; Fosbøl, E.L. One-Year Outcomes in Atrial Fibrillation Presenting during Infections: A Nationwide Registry-Based Study. Eur. Heart J. 2020, 41, 1112-1119. [CrossRef] [PubMed]

5. Boos, C.J. Infection and Atrial Fibrillation: Inflammation Begets AF. Eur. Heart J. 2020, 41, 1120-1122. [CrossRef] [PubMed]

6. Walkey, A.J.; Evans, S.R.; Winter, M.R.; Benjamin, E.J. Practice Patterns and Outcomes of Treatments for Atrial Fibrillation During Sepsis: A Propensity-Matched Cohort Study. Chest 2016, 149, 74-83. [CrossRef]

7. Klein Klouwenberg, P.M.C.; Frencken, J.F.; Kuipers, S.; Ong, D.S.Y.; Peelen, L.M.; Van Vught, L.A.; Schultz, M.J.; Van Der Poll, T.; Bonten, M.J.; Cremer, O.L.; et al. Incidence, Predictors, and Outcomes of New-Onset Atrial Fibrillation in Critically Ill Patients with Sepsis a Cohort Study. Am. J. Respir. Crit. Care Med. 2017, 195, 205-211. [CrossRef]

8. Walkey, A.J.; McManus, D. When Rhythm Changes Cause the Blues: New-Onset Atrial Fibrillation during Sepsis. Am. J. Respir. Crit. Care Med. 2017, 195, 152-153. [CrossRef] [PubMed]

9. Libby, P.; Lüscher, T. COVID-19 Is, in the End, an Endothelial Disease. Eur. Heart J. 2020, 41, 3038-3044. [CrossRef] [PubMed]

10. Russo, V.; Di Maio, M.; Mottola, F.F.; Pagnano, G.; Attena, E.; Verde, N.; Di Micco, P.; Silverio, A.; Scudiero, F.; Nunziata, L.; et al. Clinical Characteristics and Prognosis of Hospitalized COVID-19 Patients with Incident Sustained Tachyarrhythmias: A Multicenter Observational Study. Eur. J. Clin. Investg. 2020, 50, e13387. [CrossRef]

11. Sala, S.; Peretto, G.; De Luca, G.; Farina, N.; Campochiaro, C.; Tresoldi, M.; Dagna, L.; Zangrillo, A.; Gulletta, S.; Della Bella, P. Low Prevalence of Arrhythmias in Clinically Stable COVID-19 Patients. PACE Pacing Clin. Electrophysiol. 2020, 43, 891-893. [CrossRef] 
12. Rav-Acha, M.; Orlev, A.; Itzhaki, I.; Zimmerman, S.F.; Fteiha, B.; Bohm, D.; Kurd, R.; Samuel, T.Y.; Asher, E.; Helviz, Y.; et al. Cardiac Arrhythmias amongst Hospitalised Coronavirus 2019 (COVID-19) Patients: Prevalence, Characterisation, and Clinical Algorithm to Classify Arrhythmic Risk. Int. J. Clin. Pract. 2021, 75, e13788. [CrossRef] [PubMed]

13. Liao, S.C.; Shao, S.C.; Cheng, C.W.; Chen, Y.C.; Hung, M.J. Incidence Rate and Clinical Impacts of Arrhythmia Following COVID-19: A Systematic Review and Meta-Analysis of 17,435 Patients. Crit. Care 2020, 24, 690. [CrossRef]

14. Yang, H.; Liang, X.; Xu, J.; Hou, H.; Wang, Y. Meta-Analysis of Atrial Fibrillation in Patients With COVID-19. Am. J. Cardiol. 2021, 144, 152-156. [CrossRef]

15. Mulia, E.P.B.; Maghfirah, I.; Rachmi, D.A.; Julario, R. Atrial Arrhythmia and Its Association with COVID-19 Outcome: A Pooled Analysis. Diagnosis 2021. [CrossRef] [PubMed]

16. Romiti, G.F.; Corica, B.; Cangemi, R.; Basili, S.; Raparelli, V. Need for Innovative and Timely Synthesis of Evidence during Covid-19 Outbreak. Eur. J. Intern. Med. 2020, 77, 165-166. [CrossRef]

17. Viswanathan, M.; Ansari, M.T.; Berkman, N.D.; Chang, S.; Hartling, L.; McPheeters, M.; Santaguida, P.L.; Shamliyan, T.; Singh, K.; Tsertsvadze, A.; et al. Assessing the Risk of Bias of Individual Studies in Systematic Reviews of Health Care Interventions. In Methods Guide for Effectiveness and Comparative Effectiveness Reviews; Agency for Healthcare Research and Quality: Rockville, MD, USA, 2008.

18. Stijnen, T.; Hamza, T.H.; Özdemir, P. Random Effects Meta-Analysis of Event Outcome in the Framework of the Generalized Linear Mixed Model with Applications in Sparse Data. Stat. Med. 2010, 29, 3046-3067. [CrossRef] [PubMed]

19. IntHout, J.; Ioannidis, J.P.A.; Rovers, M.M.; Goeman, J.J. Plea for Routinely Presenting Prediction Intervals in Meta-Analysis. BMJ Open 2016, 6, e010247. [CrossRef]

20. Riley, R.D.; Higgins, J.P.T.; Deeks, J.J. Interpretation of Random Effects Meta-Analyses. BMJ 2011, 342, 964-967. [CrossRef] [PubMed]

21. Mavridis, D.; Salanti, G. How to Assess Publication Bias: Funnel Plot, Trim-and-Fill Method and Selection Models. Evid. Based Ment. Health 2014, 17, 30. [CrossRef]

22. Balduzzi, S.; Rücker, G.; Schwarzer, G. How to Perform a Meta-Analysis with R: A Practical Tutorial. Evid. Based Ment. Health 2019, 22, 153-160. [CrossRef]

23. Viechtbauer, W. Conducting Meta-Analyses in R with the Metafor Package. J. Stat. Softw. 2010, 36, 1-48. [CrossRef]

24. Harrer, M.; Cuijpers, P.; Furukawa, T.; Ebert, D.D. Dmetar: Companion R Package For The Guide "Doing Meta-Analysis in R". 2019. Available online: http:/ / dmetar.protectlab.org/ (accessed on 31 May 2021).

25. Lanza, G.A.; De Vita, A.; Ravenna, S.E.; D’aiello, A.; Covino, M.; Franceschi, F.; Crea, F. Electrocardiographic Findings at Presentation and Clinical Outcome in Patients with SARS-CoV-2 Infection. Europace 2021, 23, 123-129. [CrossRef] [PubMed]

26. Li, Y.; Liu, T.; Tse, G.; Wu, M.; Jiang, J.; Liu, M.; Tao, L. Electrocardiograhic Characteristics in Patients with Coronavirus Infection: A Single-Center Observational Study. Ann. Noninvasive Electrocardiol. 2020, 25, 25. [CrossRef] [PubMed]

27. Linschoten, M.; Peters, S.; van Smeden, M.; Jewbali, L.S.; Schaap, J.; Siebelink, H.-M.M.; Smits, P.C.; Tieleman, R.G.; van der Harst, P.; van Gilst, W.H.; et al. Cardiac Complications in Patients Hospitalised with COVID-19. Eur. Heart J. Acute Cardiovasc. Care 2020, 9, 817-823. [CrossRef]

28. Maeda, T.; Obata, R.; Rizk, D.; Kuno, T. Cardiac Injury and Outcomes of Patients With COVID-19 in New York City. Heart Lung Circ. 2021, 30, 848-853. [CrossRef] [PubMed]

29. Sanz, A.P.; Tahoces, L.S.; Pérez, R.O.; Ferrer, E.G.; Recalde, Á.S.; Gómez, J.L.Z. New-Onset Atrial Fibrillation during COVID-19 Infection Predicts Poor Prognosis. Cardiol. J. 2021, 28, 34-40. [CrossRef] [PubMed]

30. Peltzer, B.; Manocha, K.K.; Ying, X.; Kirzner, J.; Ip, J.E.; Thomas, G.; Liu, C.F.; Markowitz, S.M.; Lerman, B.B.; Safford, M.M.; et al. Outcomes and Mortality Associated with Atrial Arrhythmias among Patients Hospitalized with COVID-19. J. Cardiovasc. Electrophysiol. 2020, 31, 3077-3085. [CrossRef]

31. Piroth, L.; Cottenet, J.; Mariet, A.S.; Bonniaud, P.; Blot, M.; Tubert-Bitter, P.; Quantin, C. Comparison of the Characteristics, Morbidity, and Mortality of COVID-19 and Seasonal Influenza: A Nationwide, Population-Based Retrospective Cohort Study. Lancet Respir. Med. 2021, 9, 251-259. [CrossRef]

32. Poterucha, T.J.; Elias, P.; Jain, S.S.; Sayer, G.; Redfors, B.; Burkhoff, D.; Rosenblum, H.; DeFilippis, E.M.; Gupta, A.; Lawlor, M.; et al. Admission Cardiac Diagnostic Testing with Electrocardiography and Troponin Measurement Prognosticates Increased 30-Day Mortality in COVID-19. J. Am. Heart Assoc. 2021, 10, e018476. [CrossRef]

33. Santoro, F.; Monitillo, F.; Raimondo, P.; Lopizzo, A.; Brindicci, G.; Gilio, M.; Musaico, F.; Mazzola, M.; Vestito, D.; Di Benedetto, R.; et al. QTc Interval Prolongation and Life-Threatening Arrhythmias during Hospitalization in Patients with COVID-19. Results from a Multi-Center Prospective Registry. Clin. Infect. Dis. 2020. [CrossRef] [PubMed]

34. Vee, S.T.; Muhamad, D.B.; Nordin, N.B.; Ali, N.F.B.N.; Abdullah, N. Bin Clinical Characteristics of Severe Acute Respiratory Syndrome Coronavirus 2 (Sars-Cov2) Patients in Hospital Tengku Ampuan Afzan. Med. J. Malays. 2020, 75, 479-484.

35. Wang, Y.; Chen, L.; Wang, J.; He, X.; Huang, F.; Chen, J.; Yang, X. Electrocardiogram Analysis of Patients with Different Types of COVID-19. Ann. Noninvasive Electrocardiol. 2020, 25, e12806. [CrossRef]

36. Yenerçă̆, M.; Arslan, U.; Şeker, O.O.; Dereli, S.; Kaya, A.; Doğduş, M.; Öztürk, Ç.E.; Akpınar, Ç.K.; Şen, A. Evaluation of P-Wave Dispersion in Patients with Newly Diagnosed Coronavirus Disease 2019. J. Cardiovasc. Med. (Hagerstown) 2021, 22, 197-203. [CrossRef] 
37. Zylla, M.M.; Merle, U.; Vey, J.A.; Korosoglou, G.; Hofmann, E.; Müller, M.; Herth, F.; Schmidt, W.; Blessing, E.; Göggelmann, C.; et al. Predictors and Prognostic Implications of Cardiac Arrhythmias in Patients Hospitalized for COVID-19. J. Clin. Med. 2021, 10, 133. [CrossRef] [PubMed]

38. Coromilas, E.J.; Kochav, S.; Goldenthal, I.; Biviano, A.; Garan, H.; Goldbarg, S.; Kim, J.H.; Yeo, I.; Tracy, C.; Ayanian, S.; et al. Worldwide Survey of COVID-19-Associated Arrhythmias. Circ. Arrhythmia Electrophysiol. 2021, 285-295. [CrossRef]

39. D'Andrea, A.; Russo, V.; Manzo, G.; Giordano, V.; Di Maio, M.; Crescibene, F.; D'Alto, M.; Bossone, E. Association of Atrial Fibrillation and Left Atrial Volume Index with Mortality in Patients with COVID-19 Pneumonia. Eur. J. Prev. Cardiol. 2020. [CrossRef]

40. Kelesoglu, S.; Yilmaz, Y.; Ozkan, E.; Calapkorur, B.; Gok, M.; Dursun, Z.B.; Kilic, A.U.; Demirelli, S.; Simsek, Z.; Elcık, D. New Onset Atrial Fibrilation and Risk Faktors in COVID-19. J. Electrocardiol. 2021, 65, 76-81. [CrossRef]

41. Musikantow, D.R.; Turagam, M.K.; Sartori, S.; Chu, E.; Kawamura, I.; Shivamurthy, P.; Bokhari, M.; Oates, C.; Zhang, C.; Pumill, C.; et al. Atrial Fibrillation in Patients Hospitalized With COVID-19: Incidence, Predictors, Outcomes and Comparison to Influenza. JACC Clin. Electrophysiol. 2021. [CrossRef]

42. Spinoni, E.G.; Mennuni, M.; Rognoni, A.; Grisafi, L.; Colombo, C.; Lio, V.; Renda, G.; Foglietta, M.; Petrilli, I.; D’Ardes, D.; et al. Contribution of Atrial Fibrillation to In-Hospital Mortality in Patients with COVID-19. Circ. Arrhythmia Electrophysiol. 2021, 14, e009375. [CrossRef] [PubMed]

43. García-Granja, P.E.; Veras, C.; Aparisi, Á.; Amat-Santos, I.J.; Catalá, P.; Marcos, M.; Cabezón, G.; Candela, J.; Gill, J.F.; Uribarri, A.; et al. Atrial Fibrillation in Patients with SARS-CoV-2 Infection. Med. Clin. (Barc). 2021. [CrossRef]

44. Wetterslev, M.; Jacobsen, P.K.; Hassager, C.; Jøns, C.; Risum, N.; Pehrson, S.; Bastiansen, A.; Andreasen, A.S.; Tjelle Kristiansen, K.; Bestle, M.H.; et al. Cardiac Arrhythmias in Critically Ill Patients with Coronavirus Disease 2019: A Retrospective Population-Based Cohort Study. Acta Anaesthesiol. Scand. 2021, aas.13806. [CrossRef]

45. Mountantonakis, S.E.; Saleh, M.; Fishbein, J.; Gandomi, A.; Lesser, M.; Chelico, J.; Gabriels, J.; Qiu, M.; Epstein, L.M. Atrial Fibrillation Is an Independent Predictor for In-Hospital Mortality in Patients Admitted with SARS-CoV-2 Infection. Heart Rhythm 2021, 18, 501-507. [CrossRef]

46. Abe, T.; Egbuche, O.; Igwe, J.; Jegede, O.; Wagle, B.; Olanipekun, T.; Onwuanyi, A. Cardiovascular Complications in COVID-19 Patients with or without Diabetes Mellitus. Endocrinol. Diabetes Metab. 2021, 4. [CrossRef]

47. Angeli, F.; Spanevello, A.; De Ponti, R.; Visca, D.; Marazzato, J.; Palmiotto, G.; Feci, D.; Reboldi, G.; Fabbri, L.M.; Verdecchia, P. Electrocardiographic Features of Patients with COVID-19 Pneumonia. Eur. J. Intern. Med. 2020, 78, 101-106. [CrossRef]

48. Chen, Q.; Xu, L.; Dai, Y.; Ling, Y.; Mao, J.; Qian, J.; Zhu, W.; Di, W.; Ge, J. Cardiovascular Manifestations in Severe and Critical Patients with COVID-19. Clin. Cardiol. 2020, 43, 796-802. [CrossRef] [PubMed]

49. Colon, C.M.; Barrios, J.G.; Chiles, J.W.; McElwee, S.K.; Russell, D.W.; Maddox, W.R.; Kay, G.N. Atrial Arrhythmias in COVID-19 Patients. JACC Clin. Electrophysiol. 2020, 6, 1189-1190. [CrossRef] [PubMed]

50. Denegri, A.; Pezzuto, G.; D’Arienzo, M.; Morelli, M.; Savorani, F.; Cappello, C.G.; Luciani, A.; Boriani, G. Clinical and Electrocardiographic Characteristics at Admission of COVID-19/SARS-CoV2 Pneumonia Infection. Intern. Emerg. Med. 2021, 1-6. [CrossRef]

51. Harrison, S.L.; Fazio-Eynullayeva, E.; Lane, D.A.; Underhill, P.; Lip, G.Y.H. Atrial Fibrillation and the Risk of 30-Day Incident Thromboembolic Events, and Mortality in Adults $\geq 50$ Years with COVID-19. J. Arrhythm. 2021, 37, 231-237. [CrossRef] [PubMed]

52. Heijman, J.; Muna, A.P.; Veleva, T.; Molina, C.E.; Sutanto, H.; Tekook, M.; Wang, Q.; Abu-Taha, I.H.; Gorka, M.; Künzel, S.; et al. Atrial Myocyte NLRP3/CaMKII Nexus Forms a Substrate for Postoperative Atrial Fibrillation. Circ. Res. 2020, 127, $1036-1055$. [CrossRef]

53. Manjili, R.H.; Zarei, M.; Habibi, M.; Manjili, M.H. COVID-19 as an Acute Inflammatory Disease. J. Immunol. 2020, 205, 12-19. [CrossRef]

54. Salama, C.; Han, J.; Yau, L.; Reiss, W.G.; Kramer, B.; Neidhart, J.D.; Criner, G.J.; Kaplan-Lewis, E.; Baden, R.; Pandit, L.; et al. Tocilizumab in Patients Hospitalized with Covid-19 Pneumonia. N. Engl. J. Med. 2021, 384, 20-30. [CrossRef]

55. Huang, Q.; Wu, X.; Zheng, X.; Luo, S.; Xu, S.; Weng, J. Targeting Inflammation and Cytokine Storm in COVID-19. Pharmacol. Res. 2020, 159, 105051. [CrossRef]

56. Gerotziafas, G.T.; Catalano, M.; Colgan, M.P.; Pecsvarady, Z.; Wautrecht, J.C.; Fazeli, B.; Olinic, D.M.; Farkas, K.; Elalamy, I.; Falanga, A.; et al. Guidance for the Management of Patients with Vascular Disease or Cardiovascular Risk Factors and COVID-19: Position Paper from VAS-European Independent Foundation in Angiology/Vascular Medicine. Thromb. Haemost. 2020, 120, 1597-1628. [CrossRef]

57. Gencer, S.; Lacy, M.; Atzler, D.; Van Der Vorst, E.P.C.; Döring, Y.; Weber, C. Immunoinflammatory, Thrombohaemostatic, and Cardiovascular Mechanisms in COVID-19. Thromb. Haemost. 2020, 120, 1629-1641. [CrossRef]

58. Bikdeli, B.; Madhavan, M.V.; Gupta, A.; Jimenez, D.; Burton, J.R.; Der Nigoghossian, C.; Chuich, T.; Nouri, S.N.; Dreyfus, I.; Driggin, E.; et al. Pharmacological Agents Targeting Thromboinflammation in COVID-19: Review and Implications for Future Research. Thromb. Haemost. 2020, 120, 1004-1024. [CrossRef] [PubMed]

59. Zeng, Z.; Yu, H.; Chen, H.; Qi, W.; Chen, L.; Chen, G.; Yan, W.; Chen, T.; Ning, Q.; Han, M.; et al. Longitudinal Changes of Inflammatory Parameters and Their Correlation with Disease Severity and Outcomes in Patients with COVID-19 from Wuhan, China. Crit. Care 2020, 24, 525. [CrossRef] [PubMed] 
60. Smilowitz, N.R.; Kunichoff, D.; Garshick, M.; Shah, B.; Pillinger, M.; Hochman, J.S.; Berger, J.S. C-Reactive Protein and Clinical Outcomes in Patients with COVID-19. Eur. Heart J. 2021. [CrossRef]

61. Bosch, N.A.; Cimini, J.; Walkey, A.J. Atrial Fibrillation in the ICU. Chest 2018, 154, 1424-1434. [CrossRef]

62. Mortensen, E.; Metersky, M.; Atuegwu, N.; Anzueto, A. New Onset Atrial Fibrillation in Patients Hospitalized with Pneumonia. Eur. Respir. J 2019, 54, OA3307.

63. Cangemi, R.; Calvieri, C.; Falcone, M.; Bucci, T.; Bertazzoni, G.; Scarpellini, M.G.; Barillà, F.; Taliani, G.; Violi, F.; Battaglia, S.; et al. Relation of Cardiac Complications in the Early Phase of Community-Acquired Pneumonia to Long-Term Mortality and Cardiovascular Events. Am. J. Cardiol. 2015, 116, 647-651. [CrossRef]

64. Hindricks, G.; Potpara, T.; Dagres, N.; Bax, J.J.; Boriani, G.; Dan, G.A.; Fauchier, L.; Kalman, J.M.; Lane, D.A.; Lettino, M.; et al. 2020 ESC Guidelines for the Diagnosis and Management of Atrial Fibrillation Developed in Collaboration with the European Association for Cardio-Thoracic Surgery (EACTS). Eur. Heart J. 2021, 42, 373-498. [CrossRef]

65. Williamson, E.J.; Walker, A.J.; Bhaskaran, K.; Bacon, S.; Bates, C.; Morton, C.E.; Curtis, H.J.; Mehrkar, A.; Evans, D.; Inglesby, P.; et al. Factors Associated with COVID-19-Related Death Using OpenSAFELY. Nature 2020, 584, 430-436. [CrossRef]

66. Proietti, M.; Marzona, I.; Vannini, T.; Tettamanti, M.; Fortino, I.; Merlino, L.; Basili, S.; Mannucci, P.M.; Boriani, G.; Lip, G.Y.H.; et al. Long-Term Relationship Between Atrial Fibrillation, Multimorbidity and Oral Anticoagulant Drug Use. Mayo Clin. Proc. 2019, 94, 2427-2436. [CrossRef]

67. Iaccarino, G.; Grassi, G.; Borghi, C.; Ferri, C.; Salvetti, M.; Volpe Massimo, M. Age and Multimorbidity Predict Death among COVID-19 Patients: Results of the SARS-RAS Study of the Italian Society of Hypertension. Hypertension 2020, 76, 366-372. [CrossRef] [PubMed]

68. Mair, F.S.; Foster, H.M.; Nicholl, B.I. Multimorbidity and the COVID-19 Pandemic-An Urgent Call to Action. J. Comorbidity 2020, 10. [CrossRef]

69. Bikdeli, B.; Madhavan, M.V.; Jimenez, D.; Chuich, T.; Dreyfus, I.; Driggin, E.; Nigoghossian, C.D.; Ageno, W.; Madjid, M.; Guo, Y.; et al. COVID-19 and Thrombotic or Thromboembolic Disease: Implications for Prevention, Antithrombotic Therapy, and Follow-Up: JACC State-of-the-Art Review. J. Am. Coll. Cardiol. 2020, 75, 2950-2973. [CrossRef]

70. Guazzi, M.; Arena, R. Endothelial Dysfunction and Pathophysiological Correlates in Atrial Fibrillation. Heart 2009, 95, 102-106. [CrossRef]

71. Bosch, N.A.; Rucci, J.M.; Massaro, J.M.; Winter, M.R.; Quinn, E.K.; Chon, K.H.; McManus, D.D.; Walkey, A.J. Comparative Effectiveness of Heart Rate Control Medications for the Treatment of Sepsis-Associated Atrial Fibrillation. Chest 2020, 159, 1452-1459. [CrossRef]

72. Romiti, G.F.; Proietti, M. Impact of Rate Control in Hospitalized Patients with Atrial Fibrillation and Sepsis. Eur. J. Intern. Med. 2021. [CrossRef]

73. Hertanto, D.M.; Sutanto, H.; Kencono Wungu, C. Immunomodulation as a Potent COVID-19 Pharmacotherapy: Past, Present and Future. Preprints 2021. [CrossRef]

74. Romiti, G.F.; Pastori, D.; Rivera-Caravaca, J.M.; Ding, W.Y.; Gue, Y.X.; Menichelli, D.; Gumprecht, J.; Koziel, M.; Yang, P.-S.; Guo, Y.; et al. Adherence to the 'Atrial Fibrillation Better Care' (ABC) Pathway in Patients with Atrial Fibrillation. Thromb. Haemost. 2021. [CrossRef] 